\title{
Spatial Distribution of Drifted-wood Hazard following the July 2017 Sediment-hazards in the Akatani River, Fukuoka Prefecture, Japan
}

\author{
Mariko Shimizu ${ }^{1}$, Sayaka Kanai ${ }^{1}$, Norifumi Hotta ${ }^{3}$, Candide Lissak ${ }^{4}$, Christopher Gomez ${ }^{1,2, *}$ \\ ${ }^{1}$ Kobe University, Graduate School of Maritime Sciences, Laboratory of Sediment Hazards and \\ Disaster Risk \\ ${ }^{2}$ University Gadjah Mada, Dept. of Geography, Yogyakarta, Indonesia \\ ${ }^{3}$ Graduate School of Agricultural and Life Sciences, The University of Tokyo \\ ${ }^{4}$ Caen University, Dept. of Geography, Laboratory Geophen, France \\ *) Corresponding Author (e-mail: christophergomez@bear.kobe-u.ac.jp)
}

Received: 30 October 2020 / Accepted: 16 November 2020 / Published: 07 December 2020

\begin{abstract}
In recent years, heavy rainfall leading to floods, landslides, and debris-flow hazards have had increasing impacts on communities in Japan because of climate change and structural immobilism in a changing and ageing society. Decreasing the rural population lowers the human vulnerability in the mountains, but hazards can still leave the mountain to the plains and sea, potentially carrying drifted-wood. The paper aims to measure the distribution of wood-debris deposits created by the 2017 Asakura disaster and to rethink the distribution and spatial extension of associated disaster-risk zoning. For this purpose, the authors: (1) digitised and measured the distribution of drifted-wood, (2) statistically analysed its distribution, and (3) calculated the potential impact force of individual drifted timber as a minimum value. The results have shown that there is a shortening of the wood debris as they travel downstream and that the geomorphology has an important control over deposition zones. The result of momentum calculation for different stems' length show spatially differentiated hazard-zones, which limit different disaster-risk potentials. From the present finding, we can state that we (1) need to develop separate strategies for sediments and wood debris (2) and for wood hazards, zonation can be generated depending on the location and the size of the deposited trees that differs spatially in a watershed.
\end{abstract}

Keywords: drifted woods, heavy rainfall, landslide, debris flow, hazards.

\section{Introduction}

Drifted wood (DW) movement in river channels is a natural process that transfers wood debris $(>1 \mathrm{~m}$ length and $>0.1 \mathrm{~m}$ in diameter - (e.g., Wohl et al., 2010) and smaller bio-debris downstream the river catchment. The DW is recruited (a) from forested and wooded hillslopes notably from debris flows and landsides (e.g., Benda and Sias, 2003), (b) from the river-banks and (c) from previously deposited DW across the floodplain, and the recruitment is often related to planform changes due to high-energy event erosion such as flashfloods (e.g., Lucia et al., 2018). Often, it is not a linear process, and the drifted wood will have variable residence and delivery time in the catchment depending on the hydro-geomorphologic and landcover characteristics of a catchment (e.g., Iroume et al., 2020).

Scientists have reported that the progressive abandonment of agricultural land, replaced by forest plantations and forested land, as well as the overall terraforming transitions of the agricultural mountain landscapes, has been the source of historical changes in the types of hazards in Japan (e.g., Li et al., 2019), and the origin of an increase in drifted woods disaster 
risk in Japan (e.g., Shimizu et al., 2019) or in Italy for instance (e.g., Comiti, 2012). In Japan, the same trend has been observed with the population ageing and the replacement of agricultural land with forestry. The DW is often associated with sediment hazards, and as the Japanese archipelago is dominated by forested mountains (about 67\%), it often leaves a thin strip of 'flat areas' between the mountain and the sea, where the population is mostly concentrated. Then the combination of sediment and drifted-wood hazard is a common pair in Japan. Such examples have been detected in the Tohoku area, where sediment hazard coupled with DW transported $\sim 45,000$ trees during the Lionrocks typhoon. The DW of a sub-catchment of the Omoto River was composed of $15.09 \mathrm{~m}$ mean height and $0.30 \mathrm{~m}$ diameter f Hinoki (Chamaecyparis Obtusa) and Sugi (Cryptomeria Japonica) (e.g., Chaithong et al., 2018). These two tree species are particularly prone to such hazards due to their shallow root systems, offering little encroachment. In Hokkaido, damages caused by DW in the Atsubetsu River basin in the Hidaka region during Typhoon Etsuin 2003 was recruited for $70 \%$ from the riparian forest and 30\% from hillslope landslides. The source of DW, the tree species, and size were different at different locations of the catchment. In the upstream and midstream areas, DW was mostly generated by hillside collapse so that leaves, roots, and bark remained intact. In the middle to lower reaches of the river, the runoff of standing trees from the riparian forest was greater, and as we move downstream, the leaves and bark were separated from the stems. It has been supposed that this was caused by contact and collision with streambanks and worn down by stones and debris in the mudslide as they travelled downstream (e.g., Sato et al., 2006; Yamada et al., 2006).

Indeed, during torrential rains, collapsing of forest land and movement of streambed sediments often cause mudflows and debris flows, which wash away driftwood and sediment. Driftwood is one of the factors that increase the scale of damage from floods and landslides. The amount of wood runoff depends not only on the amount of rainfall and runoff water but also on the topography, geology, land cover and the amount of water in the vicinity of the river channel in the mountainous basin. It is likely to vary depending on the way the forest is managed, but in areas that have been heavily forested along the valley is also likely to increase the scale of mudslide disasters due to a large amount of driftwood runoff associated with mudslides.

Like the other environmental processes, the intensity and volume of timber (the water and sediments, for instance) can, in turn, be the origin of hazards as they impact bridges' piles (e.g., Diehl, 1997) and dwellings and infrastructures during floods (e.g., Steeb et al., 2017). Temporary log-jams in streams can also break when reaching a threshold density and create large moving "clogs" instead of singletravelling DW as shown experimentally (e.g., Chen et al., 2020). When insufficient abundance or when left to accumulate in the channel or against bridge piles, the wood debris limit the river discharge and eventually create temporary dams that can generate floods in unpredicted areas (e.g., Lyn et al., 2007; Comiti et al., 2012), as it has been demonstrated in Japan (Kimura et al., 2017). The small amount of DW can also be a hazard, especially when rivers are used as recreation areas (e.g., Conley and Kramer, 2020).

As the DW plays an essential role in rivers' ecosystem (e.g., Gurnell, 2013; Le Lay et al., 2013) and providing nutriments to the aquatic life (e.g., Benke and Wallace, 2003), attempting to remove drifted wood from the streams is not an environmentally-friendly solution, therefore, provide a better understanding of DW hazards is essential. This study aims to measure the distribution of wood-debris deposits created by the 2017 Asakura disaster and to rethink the distribution and spatial extension of associated disaster-risk zoning. 


\section{Research Method}

2.1 Research location and research context: the 2017 rainfall event in the Akatani River basin

For this study, we use Akatani River basin in Asakura City in the Fukuoka Prefecture as the study area because in the aftermath of the 2017 heavy rainfall event, there were significant structural damages occurred (Figure 1 \& Table 1). We investigated a portion of the Akatani River catchment in the Hiki-Matsusue area, also drained by the Otoishi River, upstream of Masue Elementary School (Figure 1). The Akatani River catchment used for the present research is $\sim 4.5 \mathrm{~km}$ from North to South and $\sim 4.0 \mathrm{~km}$ in the East-West direction. The watershed area is $20.1 \mathrm{~km}^{2}$, the river length is $15.5 \mathrm{~km}$, and the average riverbed slope, $1 / 35\left(1.6^{\circ}\right)$ River. The geology of the Akatani River basin consists mainly of metamorphic rocks and plutonic rocks (granodiorite). Metamorphic rocks in the Ogouchi River basin, and plutonic rocks (granodiorite) in the Otoishi River basin.
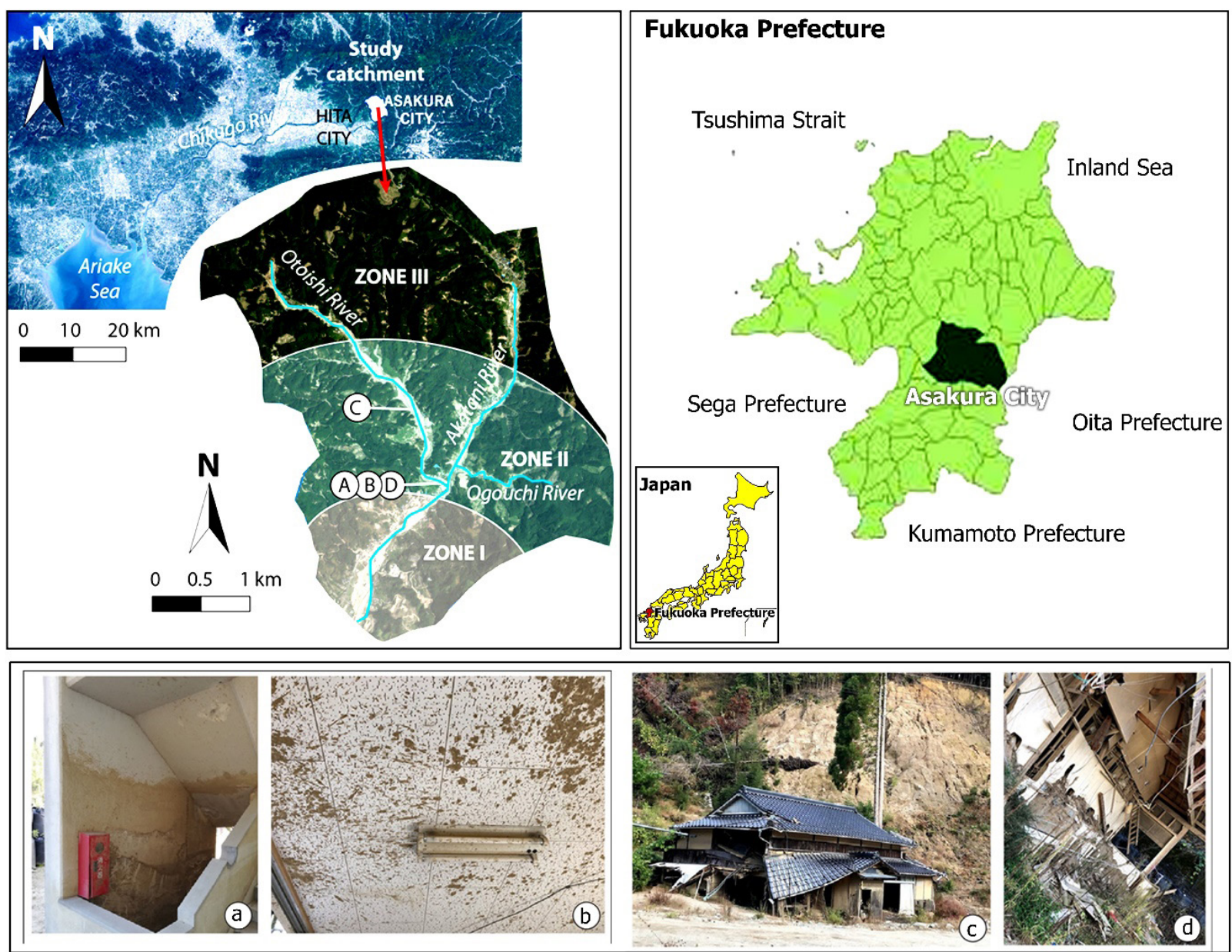

Figure 1. Location of the study area. $A, B, C$, and $D$ are locations for photographs $a, b, c$, and $d$ respectively. (a) Ground level flow mark in the outdoor staircase of Masue Elementary school (about 1.8 m high); (b) Mud projection on the ceiling of the ground floor school corridor; (c) Dwelling impacted by the side-hill mass movements and the valley flooding, upstream of Matsue Elementary School;(d) Rear of Matsue-elementary school, where the flow entered the school and destroyed the equivalent of one classroom size of the building (photos by M. Shimizu, Nov. 2018). 
Table 1. Human and Material damage of "Heavy rainfall in Northern Kyusyu on 2017

\begin{tabular}{|c|c|c|c|c|c|c|c|c|c|c|c|}
\hline \multirow{3}{*}{ Prefecture } & \multirow{2}{*}{\multicolumn{4}{|c|}{ casualties }} & \multicolumn{5}{|c|}{ Residential damage } & \multirow{2}{*}{\multicolumn{2}{|c|}{$\begin{array}{l}\text { Non residential } \\
\text { damage }\end{array}$}} \\
\hline & & & & & \multicolumn{3}{|c|}{ destruction } & \multicolumn{2}{|r|}{ flood } & & \\
\hline & dead & missing & severe & minor & total & half & partly & floor & underfloor & $\begin{array}{l}\text { Public } \\
\text { building }\end{array}$ & others \\
\hline Fukuoka & 34 & 4 & 7 & 9 & 260 & 829 & 39 & 22 & 570 & 5 & 707 \\
\hline
\end{tabular}

1000

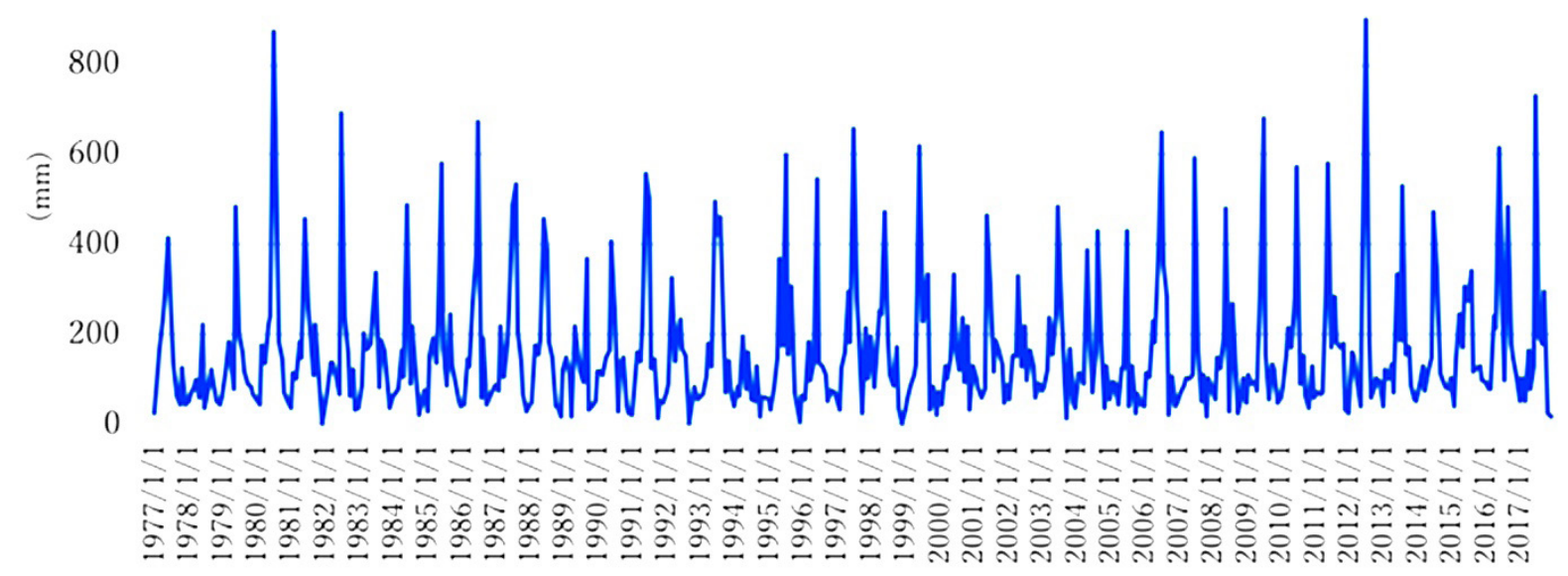

Figure 2. Monthly variation of total precipitation in Asakura 1977 2017 JMA

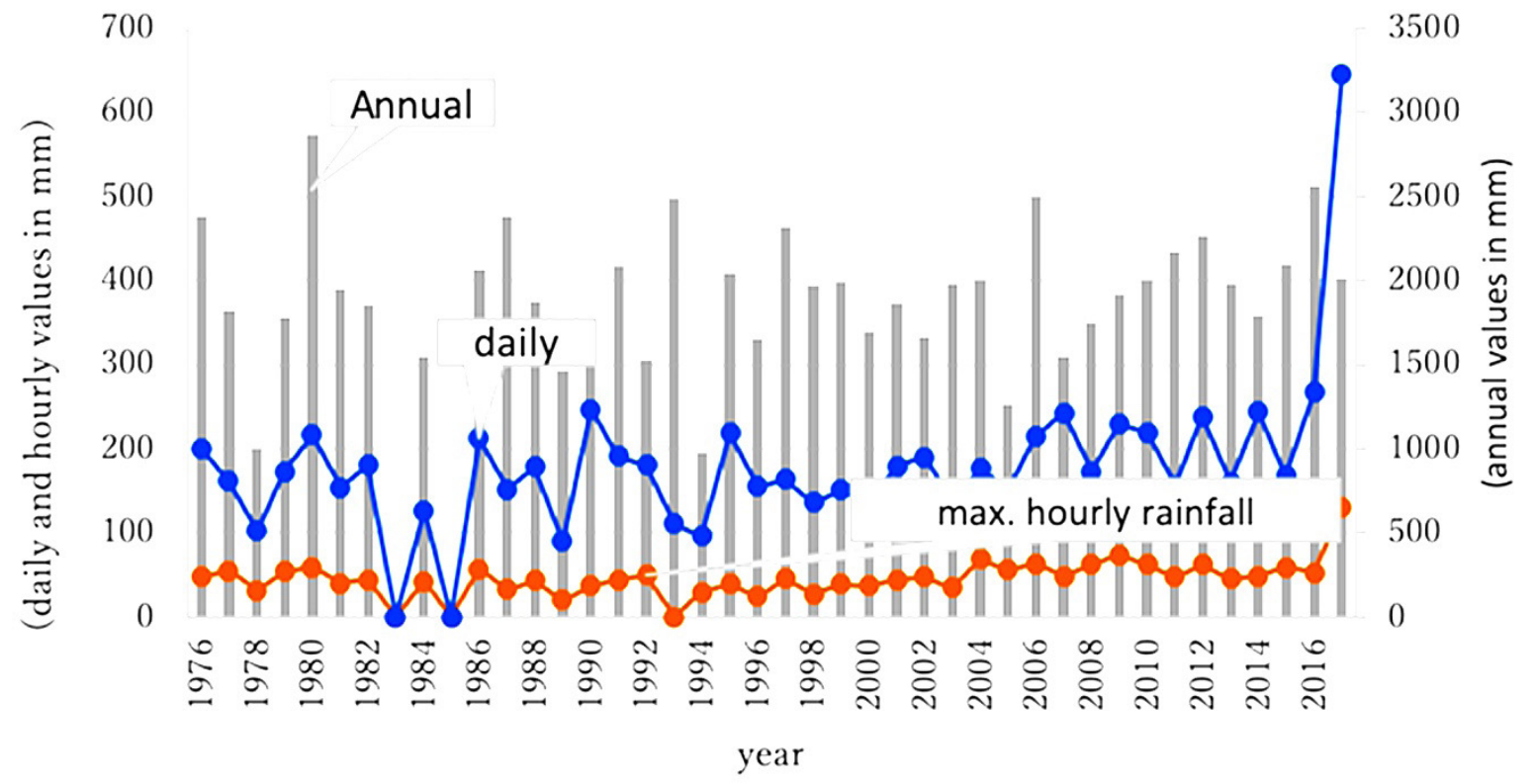

Figure 3. Annual precipitation at Asakura-City station for the period 1976-2017, showing maximum daily rainfall, Precipitation maximum for one hour. The blue curve is the maximum daily rainfall; the orange curve is the hour maximum rainfall; the grey bar chart shows the annual precipitation.

We divided the basin into three main units, a downstream unit, a midstream unit, and an upstream unit, to account for the variability in the basin's physiography and the change in water concentration. This division is arbitrary and set up to observe the potential variations in the DW deposits (Figure 1).

The monthly rainfall data in Asakura City (Figure 2) during the period 1977-2017 (rain gauge data from the Japanese Meteorological Agency) 
shows that the average monthly maximum precipitation is just shy of $\sim 114 \mathrm{~mm}$ over the 40 years record, with monthly rainfalls exceeding $800 \mathrm{~mm}$ only twice in 40 years and 9 times for $600 \mathrm{~mm}$ events during the same period (Figure 2). During the July 2017 event (J17E), the daily rainfall reached $516 \mathrm{~mm}$. Consequently, J17E was not an exceptional rainfall event at the monthly and yearly scale, but it was at the shorter-time scale (Figure 3). Indeed, in 40 years, the daily rainfall never exceeded 300 $\mathrm{mm}$, and during the J17E, it reached two times the previous maximum with $516 \mathrm{~mm}$. At the hourly scale, it was also the first time in 40 years that it reached $>100 \mathrm{~mm} / \mathrm{h}$.

\subsection{Data acquisition and digitization}

The method used in the present study is threefold: (1) data acquisition using GIS from aerial photographs; (2) Statistical model building of the DW distribution and (3) Physical modelling of DW impacts to improve hazard zoning.

Using the aerial photographs generated by the GIS in the aftermath of the Asakura event, the authors manually digitized 5812 DW individually recognizable from the DW deposits. The choice of the manual method was motivated by the absence of an automated computer-vision system that is viable for the constant and error-free identification of tree debris. As human operators also make an error, the first author performed the entire digitization process. This is meant to limit the human error variability between operators.

For this task, the authors used the QGIS tools to create a shapefile of the "trees" and count the driftwood. The length of each DW was also calculated and stored using the attribute table of the shapefile. Although the total number of legible DW digitized for this study is 5812, it is still a small portion of the total number of trees, and the authors have treated the DW debris data as a sample of observations from a statistical distribution of DW.

Furthermore, the watershed was divided into three parts, the headwater part, the main zone, and the river-mouth zone, which correspond to three zones we made of equal length $(1,500 \mathrm{~m})$, so that the main channellength equivalent of the study area is $4,500 \mathrm{~m}$. In the present study we name those ZONE I, II and III starting downstream. The spatial measures and characteristics of the driftwood and wood debris were converted into a set of attributes, and the data were analyzed further in Excel.

\subsection{DW distribution analysis using Monte- Carlo bootstrapping fitting skewness and kurtosis}

Although a large number of statistical distributions in environmental sciences follow normal distributions, the distribution of sediments in channels or in the present case DW, is a function of an energy gradient, creating a dissymmetry and a tail in the dataset. To best chose a probability density function that models the sample distribution, the authors used the Cullen and Frei Graphic method (e.g., Cullen and Frei, 1999) that relates the square of the skewness value to the kurtosis, with the skewness of a sample defined as Equation 1 and the kurtosis defined as Equation 2, where $n$ is a number of observations taken from the sample, defines a set of empirical moments calculated for ith observations of the variable $v$ using Equation 3, so that is from $n$ observations of the variable $v$, with being the mean of the observations.

$$
\begin{aligned}
& S_{k}=\frac{\sqrt{n(n-1)}}{n-2} * \frac{m_{3}}{m^{\frac{3}{2}}} \\
& \begin{array}{l}
k_{r} \\
(3)
\end{array}=\frac{n-1}{(n-2) *(n-3)}\left((n+1) * \frac{m_{4}}{m_{2}{ }^{2}}-3(n-1)\right)+3
\end{aligned}
$$


$v=\frac{\sum_{i=\mathbf{1}}^{n}\left(v_{i}-\bar{v}\right)^{k}}{n}$

The skewness is a measure of the dissymmetry - compared to a normal distribution - and the kurtosis is a measure of the tail of the distribution (i.e., how important it is in comparison to the normal distribution). As those estimators provide a description of the shape of the distribution, it is thus possible to use the two to define the closest probability density function.

Because the distribution is assumed not to be normal, nor the z-test nor the t-test could be used, and bootstrapping was used instead. Bootstrap is a nonparametric Monte Carlo simulation method that estimates the distribution of a population by resampling it (e.g., Efron, 1979; Efron, 1981) from the histogram of the sampled data. For the present contribution, the authors performed 1,000 bootstraps from the sample and plotted those in the Curley and Frey graphic. The model was then generated in $\mathrm{R}$ using a fitting package using this graphic to choose the bestfitted distribution (e.g., Delignette-Muller \& Dutang, 2020).

\subsection{Analysis of potential DW single-timber impact force}

As we are interested in the hazard and the disaster risk, we then used the digitized drifted wood to calculate the mass of the wood debris using existing conversion tables, and we then calculated the potential impact force of the different trees, depending on their location. Firstly, the authors imported the digitized data in MATLAB (MathWorks ${ }^{\circledR}$ ) numerical analysis software to calculate each identified individual wood debris mass. Then, the velocity of the flow that transported and deposited the wood debris was calculated using the Manning equation, considering that trees float both on water and or on denser flows, allowing to simplify the approach. Using a scenario-based analysis for hazard analysis purposes, we calculated the velocities for flow depth of $1 \mathrm{~m}$ and $1.5 \mathrm{~m}$ for three sectors of slopes: $5^{\circ}, 10^{\circ}$, and $15^{\circ}$. Then, combining the velocity data to the mass of the driftwood, the momentum of the driftwood was calculated for each of the six scenarios.

To estimate the momentum of the moving driftwood, we consider the velocity of the mudstone flow containing the driftwood. Following Shimizu et al. (2018) method of calculating the velocity of a mudslide flow, the velocity of the mudslide flow is shown in Equation 4 calculated by the Manning equation, where $v$ is velocity $[\mathrm{m} / \mathrm{s}], n$ is roughness coefficient, $h$ is depth of the flow[m], and $\theta$ is slope [degree]. The roughness coefficient $n$ is set to 0.1 , and the depth of the flow is set to $1 \mathrm{~m}$ and $1.5 \mathrm{~m}$ in two cases. We considered the following. In this case, in the damage classification of the Akatani River basin in Asakura City, the slope of the topographical surface on which the house is built was mostly in the range of 5 to 15 degrees, so the slope was calculated at 5 degrees, 10 degrees, and 15 degrees. Finally, we compared the obtained data to the energy necessary to knock down a wooden house.

$v=\frac{1}{n} h^{\frac{2}{3}}(\sin \theta)^{\frac{1}{2}}$

The length of the driftwood is calculated from the diameter at breast height of the driftwood. A clear proportional relationship is found between the diameter and length of the driftwood, and the regression equation is given by Equation 5 (Shimizu et al., 2018), wherein the Equation 5, $d$ is the diameter $(\mathrm{m})$ of each individual DW, and $L$ is the length (m). Using the relation between the mass of trees for Sugi (Equation 6) and Hinoki (Equation 7) (Kanzaki in Gomez, 2018), the mass of each DW was considered, where $M$ is the mass in $(\mathrm{kg})$ and $d$ the diameter in $(\mathrm{m})$.

$$
\begin{aligned}
& d=0.028 L-0.165\left(r^{2}=0.71\right) \\
& M=0.02723 d^{2.295} \\
& M=0.0274 d^{2.295}
\end{aligned}
$$




\section{Results}

3.1 Drifted wood characterization and distribution simulation

A total of 5,812 pieces of DW were digitized, with a distribution of debris between $1 \mathrm{~m}$ (the lower limit artificially chosen for DW) and a few exotic sizes at $35 \mathrm{~m}$. The sample distribution is unimodal, with a majority of DW between 2 and $10 \mathrm{~m}$ in length. This is further legible from the cumulative distribution of the DW, where the interquartile of the DW length is comprised between the values of 2 and $10 \mathrm{~m}$ (Figure 4), with $80 \%$ of the DW being $<14 \mathrm{~m}$ in length. This translates numerically in a mean length of the DW was $8.63 \mathrm{~m}$, and the mode was $5 \mathrm{~m}$.

The probability density function was defined from the Cullen and Frey graphic to be a gamma distribution using the observation distribution's statistical parameters (Figure 5a). In order to test this graphical hypothesis, the parameters of density, quantiles, probability density functions, and the probabilities of the sample and the calculated distribution were compared for the goodness of fit (Figure 5b).

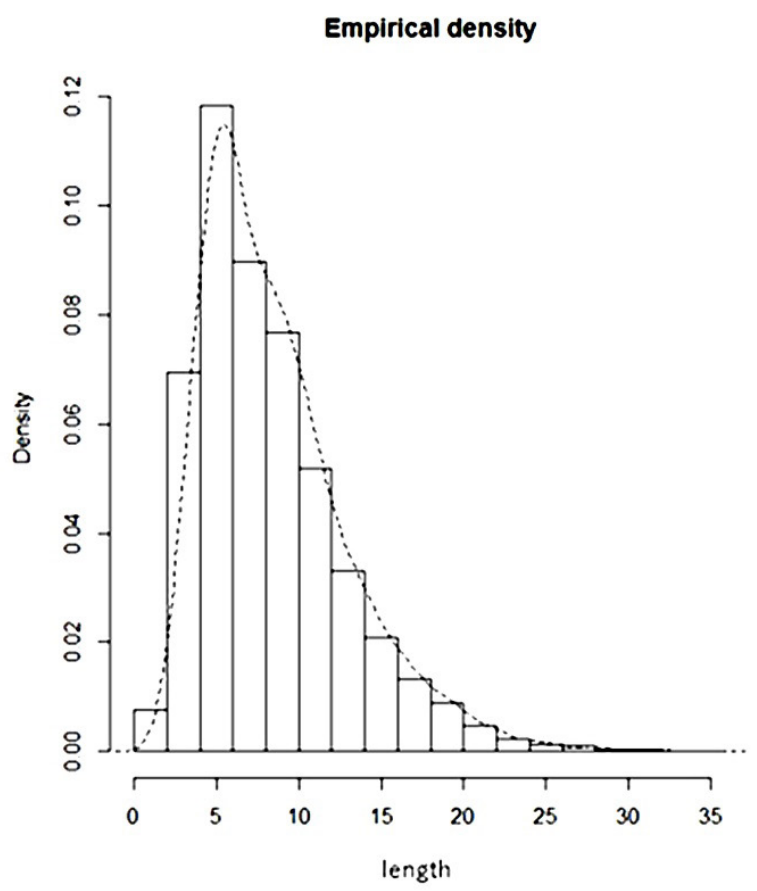

The gamma distribution best fitted the dataset, with a shape parameter of 4.034 and standard error of 0.0719 , with a rate value of 0.4675 and a standard error of 0.0088 , i.e., for a gamma probability density function (see Equation 8) with the relation to the sample set to be for the mean of the tree length (see Equation 9), and with the variance (see Equation 10). Hence, from a forested watershed of similar yet unknown in the present contribution and to be defined in future work - geomorphologic parameter(s) and with a known distribution of tree size or age, one can estimate the distribution of the wood debris to follow a gamma distribution.

$$
\begin{aligned}
& \mathrm{fx}(\mathrm{v})=\frac{0.4675(0.4675 * \mathrm{v})^{4.034-1}}{(4.034)} \mathrm{e}^{-0.4675 * \mathrm{v}} \\
& \overline{\mathrm{v}}=\frac{\mathrm{k}}{\mathrm{t}}=\frac{4.034}{0.4675}=8.6289[\mathrm{~m}] \\
& \sigma_{\mathrm{v}}{ }^{2}=\frac{\mathrm{k}}{\mathrm{t}^{2}}=18.457[\mathrm{~m}]
\end{aligned}
$$

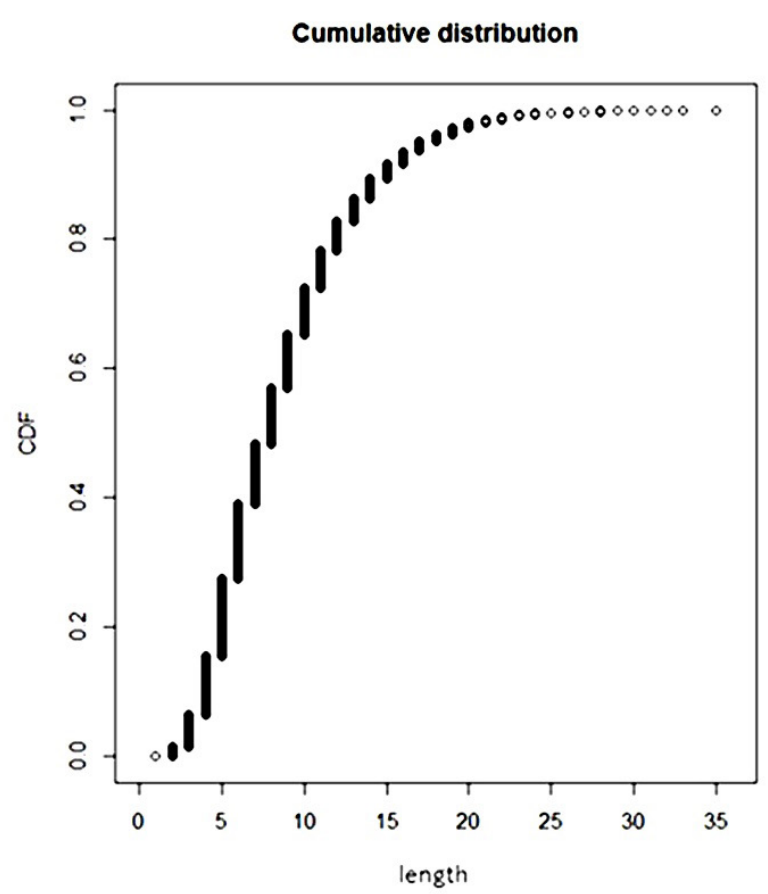

Figure 4. Distribution of the sampled DW length, with the Empirical density showing strong right side skewness, and the cumulative distribution. 


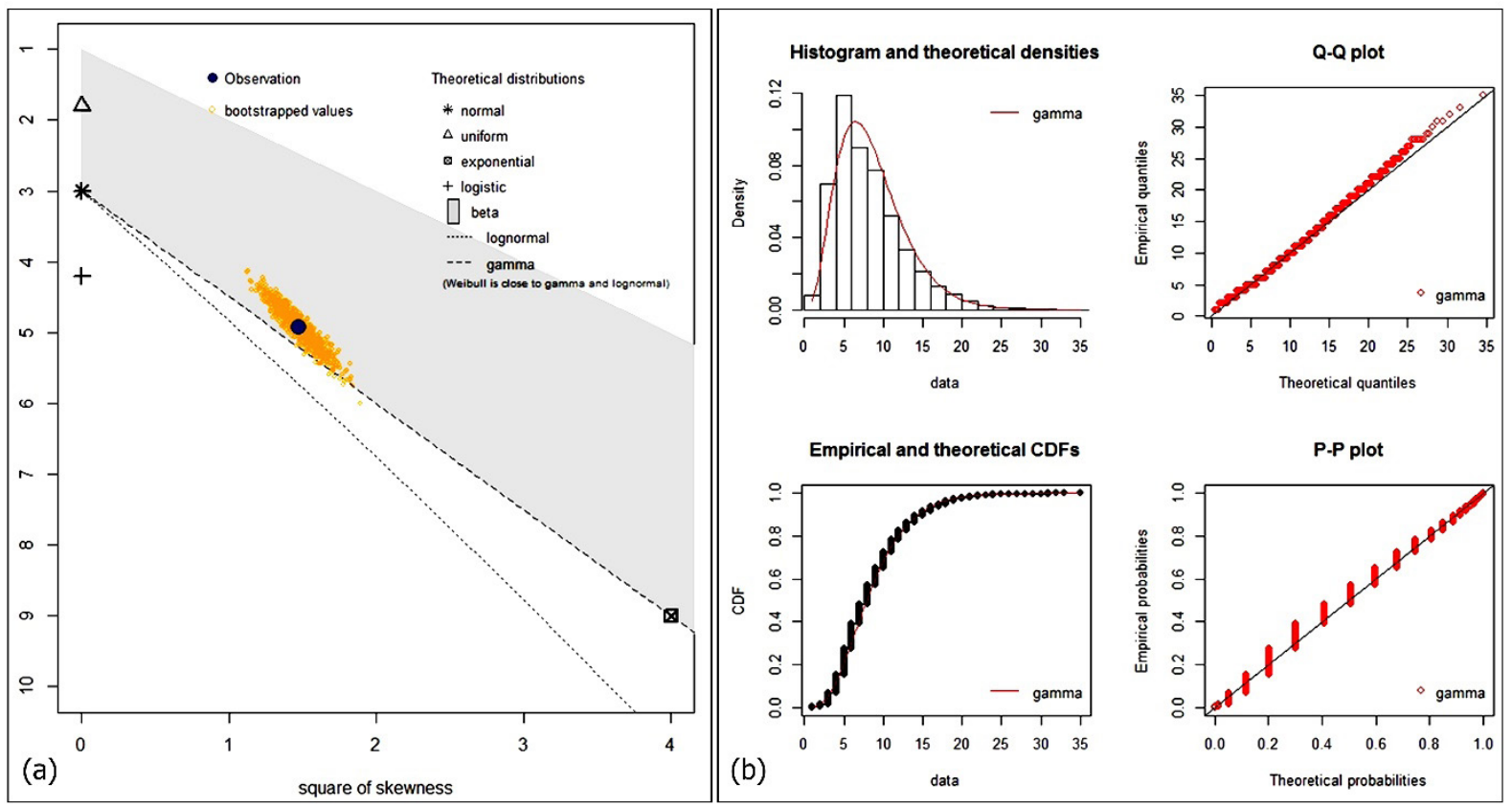

Figure 5. The probability density function and the goodness of fit between theoretical and empirical densities. (a) The Cullen and Frey Graphic plotting the kurtosis against the square of the skewness using the observation and bootstrapped values, showing that the population is closest to a gamma distribution, which should be chosen to model the dataset. (b) Probability parameters comparing the observed and the model dataset, using a gamma probability distribution $-Q$ stands for quantile, CDFs the Cumulative Density Function and, $P$ the Probability.

In the four statistical plots (Figure $5 b$ ), the data in red are those from the applied gamma distribution function, while in black are either the data or the 1:1 relation (Q-Q plot and P-P plot). The histogram and theoretical densities compare the density of the data (the length of the trees in $\mathrm{m}$ ) to the density from the gamma function; the Q-Q plot compares the quantiles of the gamma function against those calculated from the dataset, the CDF is the density function for the fitted distribution and for the data (the data is represented as black dots, while the gamma function is the red line). Finally, the P-P plot compares both probabilities with the gamma-distributed points against the data values (or empirical values).

\subsection{Sub-watershed distribution between} the 3 physiographic units

Recognizing that the DW is transported in a downstream direction, but with also tributary entries along the channel, and with almost a mono-specific forestry activity, trying to relate the deposited tree to a plot is an arduous task, but we can still define zones with more or less deposition, and eventual change in these deposition patterns within the basin (Table 2). More than half of the driftwoods are consolidated in ZONE II. This may be due to the overlap of the confluence of Otoishi-river and Akatani river in ZONE II.

The distribution of driftwood length and cumulative proportions is shown for each section (Figure 6). For the most downstream ZONE I (0 to $1500 \mathrm{~m}$ ), there has been a total of $423 \mathrm{DW}$, or $7.28 \%$ of the total number of the DW. The average length of driftwood was $7.12 \mathrm{~m}$, with the mode being $5 \mathrm{~m}$ and the median being $6 \mathrm{~m}$ (Table 3). The most extended piece of DW observed in this ZONE is $25 \mathrm{~m}$, and the majority of DW has been measured between 2 and $16 \mathrm{~m}$ in length. In ZONE II (distance from the mouth of the river is $1500-3000 \mathrm{~m}$ ), the total number of driftwood trees was 3081 , or $53.01 \%$ of the total digitized. The mean length of the DW is 8.18 $\mathrm{m}$, but the mode is the same as in ZONE I: $5 \mathrm{~m}$. The median is $7 \mathrm{~m}$, and the largest number of driftwoods was 4-6 $\mathrm{m}$ in length, with 727 items, 
accounting for about $12.5 \%$ of the total number of driftwoods in ZONE II. It was 5.72 times more than the same length ZONE I (127 trees) and 1.98 times more than the ZONE III (368 trees). The ZONE III (distance from the mouth of the river is $3000-4500 \mathrm{~m}$, i.e., the upstream area) holds $39.71 \%$ of the total number of DW (i.e., $2308 \mathrm{WD}$ ). The mean is $9.51 \mathrm{~m}$, the mode is $6 \mathrm{~m}$, and the median is $9 \mathrm{~m}$. The majority of the DW is 2-16 m long, as in ZONE I and II.

Table 2. Driftwood length statistics (by ZONE)

\begin{tabular}{ccccccc}
\hline ZONE & number & Average & Mode & Median & min & Max \\
\hline I & $423(7.28 \%)$ & 7.12 & 5 & 6 & 2 & 25 \\
II & $3081(53.01 \%)$ & 8.18 & 5 & 7 & 1 & 35 \\
III & $2308(39.71 \%)$ & 9.51 & 6 & 9 & 2 & 33 \\
Total & $5812(100 \%)$ & 8.63 & 5 & 8 & 1 & 35 \\
\hline
\end{tabular}

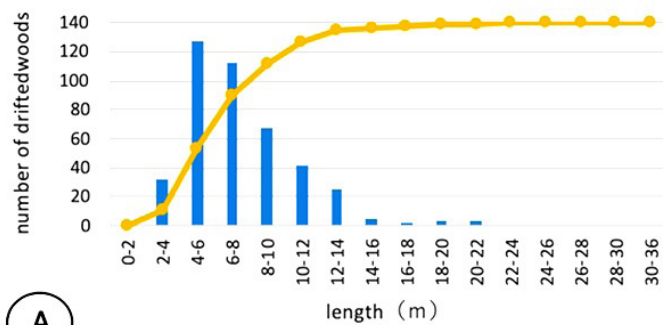

(A)

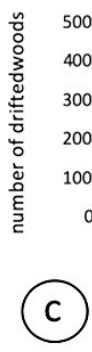

Figure 6. Length distribution of the DW by ZONE: (A) ZONE I - 0 to $1500 \mathrm{~m}$ from the catchment exit, (B) ZONE II - $1500 \mathrm{~m}$ to $3000 \mathrm{~m}$ from the catchment exit, and (C) ZONE III: $3000-4500 \mathrm{~m}$ from the catchment exit.

Table 3. Number of DW per length for the ZONE I, II, and III.

\begin{tabular}{cccc}
\hline Length $(\mathbf{m})$ & ZONE I & ZONE II & ZONE III \\
\hline $0-2$ & 32 & 7 & 0 \\
$2-4$ & 127 & 727 & 86 \\
$4-6$ & 112 & 637 & 367 \\
$6-8$ & 68 & 493 & 461 \\
$8-10$ & 42 & 376 & 426 \\
$10-12$ & 26 & 222 & 337 \\
$12-14$ & 5 & 147 & 221 \\
$14-16$ & 2 & 94 & 159 \\
$16-18$ & 4 & 63 & 102 \\
$18-20$ & 3 & 28 & 58 \\
$20-22$ & 1 & 19 & 41 \\
$22-24$ & & & 20 \\
\hline
\end{tabular}




\begin{tabular}{cccc}
\hline Length $(\mathbf{m})$ & ZONE I & ZONE II & ZONE III \\
\hline $24-26$ & 1 & 9 & 12 \\
$26-28$ & 0 & 1 & 8 \\
$28-30$ & 0 & 3 & 6 \\
$30-36$ & 0 & 2 & 4 \\
Total & 423 & 3081 & 2308 \\
\hline
\end{tabular}

DW population distribution every 250 stems

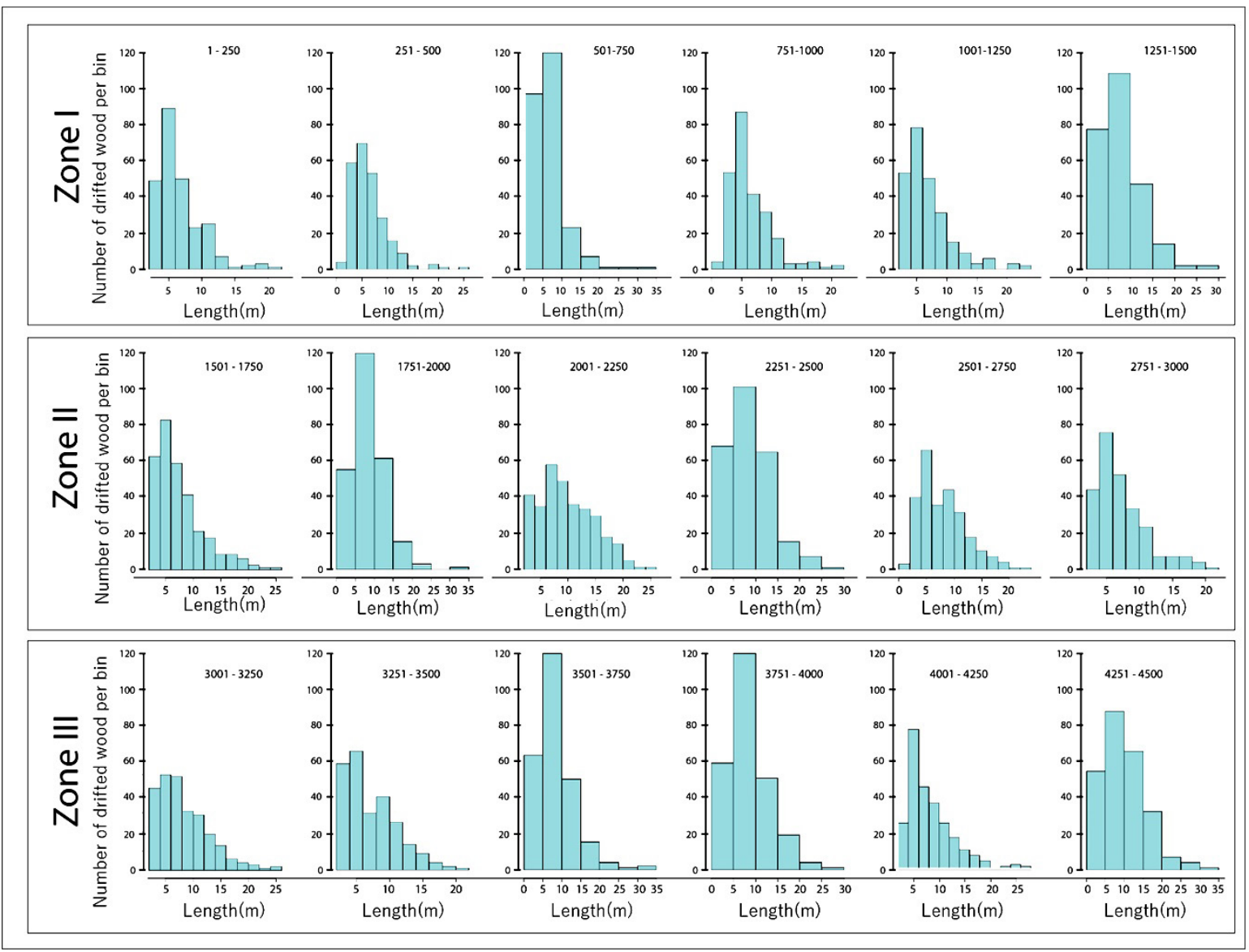

Figure 7. DW distribution every 250 samples starting downstream and moving upstream ward. Each histogram represents a sample of 250 stems, except the one furthest upstream that includes the 5,500 to the 5,812 stems. This visual provides insights into the spatial variation of the different lengths of drifted wood. Zone I, II, and III are specified on the field-research map (Figure 1).

In order to take into account the variability of DW density along the stream, spatially contiguous bins of 250 DW were generated and treated as separate statistical populations (Figure 7). The distribution shows in every section a unimodal distribution with the mode systematically between 5 and $10 \mathrm{~m}$. Despite this apparent homogeneity, some distributions are dominated by one bin in the statistical distribution (e.g., 501 - 750), while other locations are more equally spread in term of timbers' lengths (e.g. 1-250), where the mode is less differentiated from the rest of the distribution (Figure 7).

This difference in the spread and its regularity across the different tree length is best represented by the Kurtosis and the skewness of the distributions (Figure 8). The skewness and 
the kurtosis of the all catchment distribution is decreasing towards the headwater, with one progressive trough centered on the 2001 $2250 \mathrm{~m}$ section, showing that this section has a mixture of DW of different lengths.

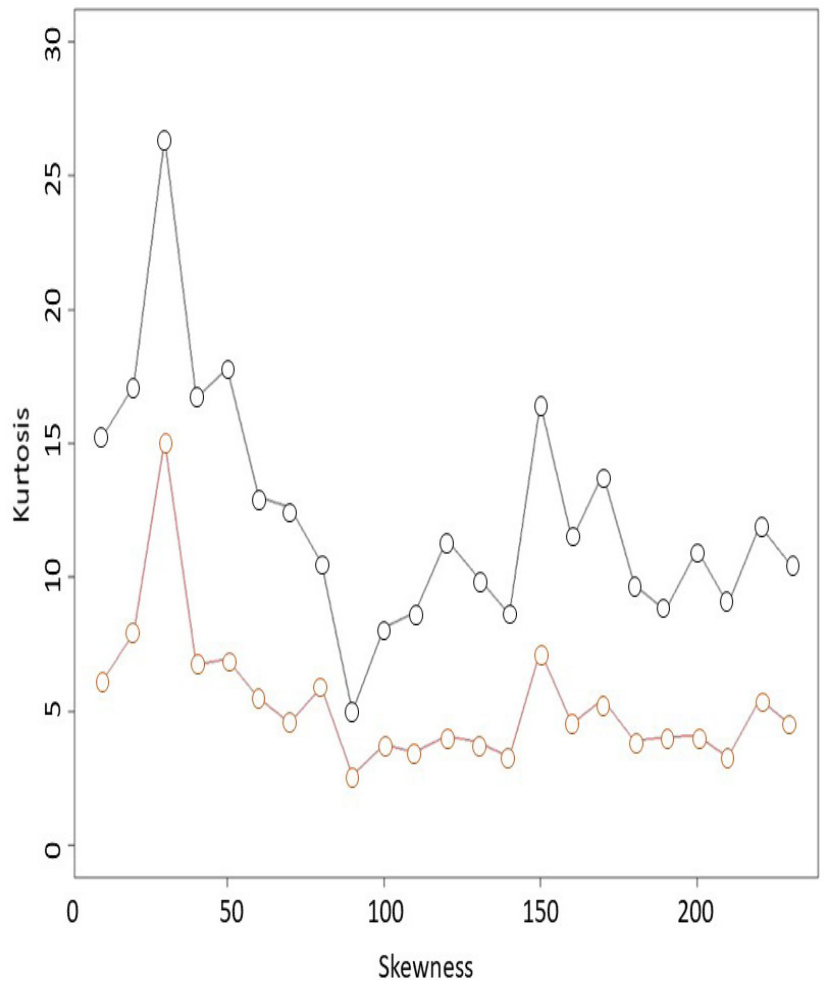

Figure 8. Distribution of the Kurtosis and the skewness for each of the different graphics provided in Figure 7, i.e., each point is calculated from each group of DW's skewness and kurtosis. The first peak corresponds to the 501 - 750 first DW, while the second peak is $3001-3750$.

In summary, the DW's statistical and geospatial distribution shows that the lengths of the DW reduce with the distance to the exit of the watershed. The shortest pieces of timber are statistically located in the lower part of the catchment (zone I), while the pieces of timber are statistically longer in the upstream zones (Zones II, and III). As the skewness and Kurtosis are decreasing upstream, it further shows that the tail effect is lower upstream, with a more homogeneous mixing. In other words, it is mostly short pieces of timber that reach the downstream ward. In detail, the distribution of lengths and the tail effects are not changing linearly within the basin, and they also present one to two thresholds (Figure 7 and Figure 8).

\section{Discussion}

\subsection{Discussion of the DW distribution}

From ZONE I to III, the average length of WD in ZONE I was $7.12 \mathrm{~m}$, while ZONE II was $8.18 \mathrm{~m}$ and ZONE III is $9.51 \mathrm{~m}$. Thus, the average length of the distributed driftwood increases, with the difference between the mean values between zone I and III being $2.39 \mathrm{~m}$. Furthermore, the number of short length driftwood increases downstream ward. Because the forested slopes are made of homogenous tree plantations, the shortening can be associated with a progressive breakage of the tree stems.

The shortening can be explained through the abrasive contact of the driftwood with the riverbanks, and because of the mixing with mud, rocks, and other rubbles in the channel during transport. Moreover, the interaction with engineering structures such as bridges can cause extra stress on the wood debris, leading to their breakage. Upstream in the catchment, the accumulated water is much lower, and the fallen trees do not travel such long distances and also have fewer chances to get broken into smaller pieces. It is, therefore, the combination of travel distance and the lack of accumulated water that can be potentially put forward as an explaining factor.

A third reason, however, is that the energy of the flow is lower downstream, so that the number of driftwoods carried is lower, and although the long driftwood is less than the mass of the downstream area, driftwood does not occur in the original sense of the word, but as a special case, the large size of the wood may have made it difficult to transport.

If we consider the longest tree stems (because we estimated that its mass would create potentially significant damage), the arrival rate is only slightly more than $3 \%$, while the incoming rate in zone II and zone III are much more significant, more than ten times this value (Figure 9). 


\subsection{Timber's lengths and WD impact force}

To further discuss the importance of the size of the transported driftwood, we analyzed the potential impacts for single WD on timber dwellings, typical of mountainous watersheds in Japan.

\subsubsection{Momentum of impact force}

For momentum calculation, the velocity was calculated using Manning's equation Equation 4 using a roughness coefficient $\mathrm{n}$ set to 0.1 and different flow-depths estimated to be 1 $\mathrm{m}$ and $1.5 \mathrm{~m}$ on submerged river-banks. We also assumed that the timber was floated over the water without velocity loss, which may provide over-estimated values, which is an acceptable

assumption for hazard purposes. Table 4. shows $\mathrm{P}=\mathrm{Mv}$ the results of the velocity calculations for the six cases with a total of six combinations of slope and water depth. The estimated velocities ranged from $3.0 \mathrm{~m} / \mathrm{s}$ to $6.7 \mathrm{~m} / \mathrm{s}$.

The momentum of the driftwood, $P\left(\mathrm{~kg}^{*} \mathrm{~m} / \mathrm{s}\right)$, was simply approximated as expressed in Equation 11, where $M$ is the mass of the driftwood $(\mathrm{kg}), v$ : velocity of the driftwood in the mudflow $(\mathrm{m} / \mathrm{s})$. The momentum has been calculated by multiplying the mass of each length of the driftwood by the velocity of the flow approximated from the Manning's equation (Table 4). Figure 10a and Figure 10a show the result of the calculation described below.

Table 4. Estimated velocities of the DW travelling on the flow.

\begin{tabular}{ccccccc}
\hline Estimated velocities of flow transporting DW from Manning's equation \\
\hline Slope $\left({ }^{0}\right)$ & \multicolumn{2}{c}{5} & \multicolumn{1}{c}{10} & \multicolumn{2}{c}{15} \\
Depth $(\mathrm{m})$ & 1 & 1.5 & 1 & 1.5 & 1 & 1.5 \\
Velocity $(\mathrm{m} / \mathrm{s})$ & 3.0 & 3.9 & 4.2 & 5.5 & 5.1 & 6.7 \\
\hline
\end{tabular}

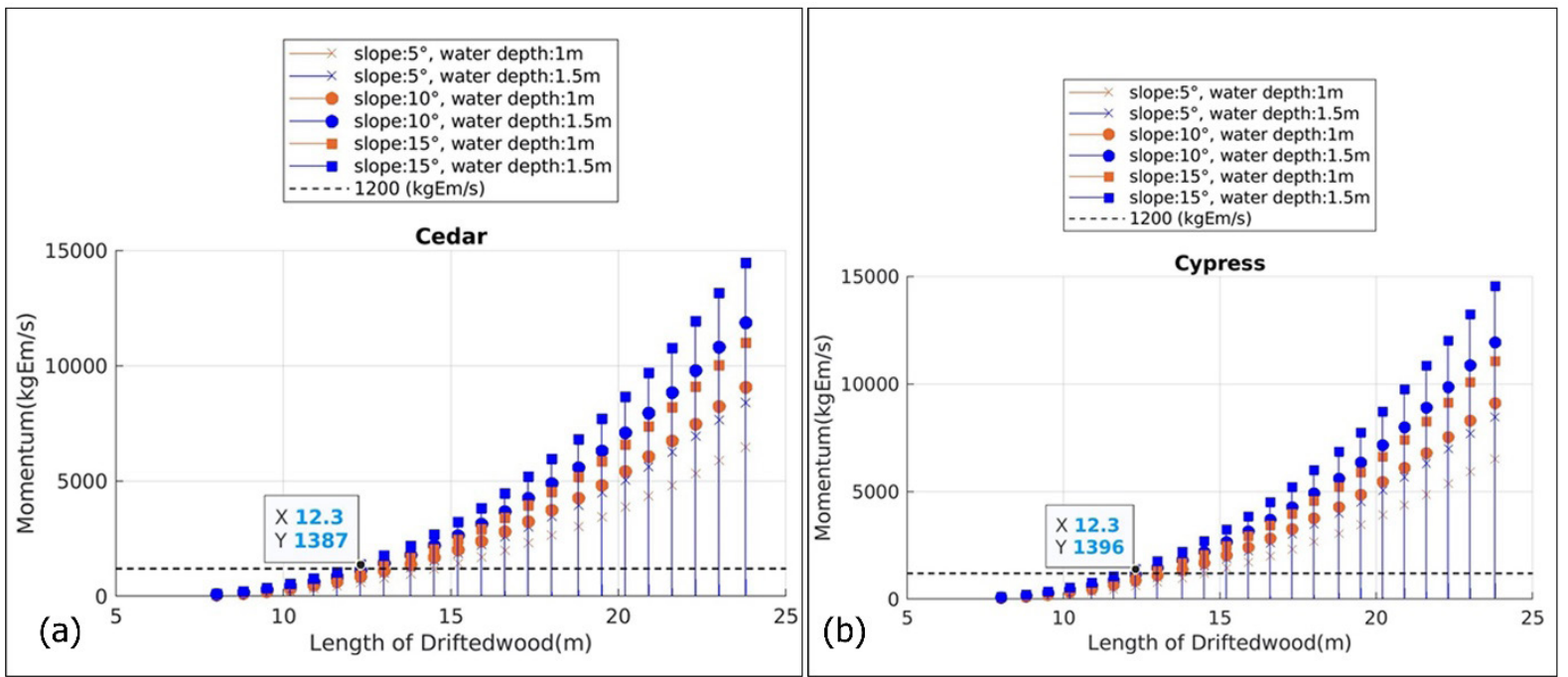

Figure 10. Momentum calculation results for drifted wood. Type of wood: (a) Cedar, (b) Cypress.

\subsubsection{Discussion of the impact force when the driftwood collides with buildings}

Figure 10a and Figure $10 \mathrm{~b}$ show that the length of the timber pieces is essential to separate the impact levels of timber on houses. Thus, the same DW should be considered differently depending on the local conditions.
For instance, only $3 \%$ of the DW in ZONE I are $>12.3 \mathrm{~m}$ so that the disaster risk level is relatively low downstream. However, in the two ZONE II and III, $46.91 \%$ and 50\% exceed the same threshold with much steeper slopes, respectively, increasing the potential hazards and disaster risk. Based on previous work 
summarised in Shimizu et al. (2018), the limit of momentum at the impact that a wooden house can safely withstand is about $1200 \mathrm{~kg} . \mathrm{m} / \mathrm{s}$ or under the assumption of a short $1 / 10$ of a second impact $120 \mathrm{~kg}$-force meter. This value represents a $100 \%$ chance of perforation in a timber board (Blong, 1981).

Besides a linear patternalong the upstreamdownstream gradient, zones of confluences have an important impact in controlling the distribution of DW. For the present study area, Zone II includes the confluence of two streams, where DW are numerous and also present long length (where the trough of Figure 8 is located), and therefore DW is considered to have been concentrated in this location, modifying the general distribution pattern.

The hazard was further emphasized by the presence of large sub-horizontal space that was good building ground, increasing vulnerability in Zones I and II. By comparison, Zone III, although it displays steep slopes and a large amount of long DW, is a zone of lower potential disaster risk, as it was not an area easy to develop. The disaster risk is in this way, statistical data are of course, necessary to determine the risk level, but it is also important to consider the human reality to understand the data fully.

In the presentcase, wehave only considered the potential impacts of trees, but the reality is much more complex, as the distribution of houses influences how many houses can be impacted, and also the distribution of houses influences the flow itself, as it was shown by Nakatani et al. (2016) for debris flows.

\section{Conclusion}

There are various factors such as the shape and size of driftwood, length of outflowing driftwood, and outflowing driftwood materials are required when considering driftwood control measures. These documents are required to be prepared for the following: trees on the forest slope near the point of driftwood generation after the disaster, driftwood deposited in flood plains, and driftwood deposited on the fan. When determining the disaster risk level, the geology, topography, population density, and age range of the inhabitants should be taken into account. It is challenging to set a consistent risk level across the country, and it is necessary to consider the risk level for each region. It is necessary to establish a new setting for the study. We need to improve our disaster-prevention capability in normal times to evacuate appropriately in the event of a disaster of the same magnitude or even more significant, without letting the experience of this disaster fade away.

\section{Acknowledgments}

The present contribution was funded by the Kakenhi Kiban A $18 \mathrm{H} 03957$ and the international collaboration was funded by the International Collaboration fund of the Graduate School of Maritime Sciences at Kobe University. The present work is part of the research of Mariko Shimizu for the obtention of her Master degree.

\section{Supplementary material}

1. Aerial photograph of Akatani basin, Asakura city from T.UCHIDA (N I L I M)

2. Cabinet Office, Fire Department information (as of 16:00 on August 21, 2017). "Heavy Rainfall Associated with the Rainy Season Front from June 30 and Damage Caused by Typhoon No. 3"

3. http://www.bousai.go.jp/updates/ h29typhoon3/pdf/h290821_29taifu03_37. pdf , 2018.11

4. Fire Disaster Management Agency (as of 2017.11/2), 2017 White Paper on Fire Service, www.fdma.go.jp/html/ hakusho/h29/h29/html/s1-2-2.html, 2018.11

5. Fukuoka Prefecture ,Report on the Verification of Disaster Response to the Northern Kyushu Heavy Rainfall in July 2017 (March 2018), https://www. bousai.pref.fukuoka.jp/spc/images / H29hokubugouu.pdf , 2018.12

6. GSI,2017,Information on the torrential rains in northern Kyushu in July 2017 www.gsi.go.jp/BOUSAI/H29hukuoka_ 
ooita-heavyrain.html, 2019.11

7. GSI.Map, https://www.gsi.go.jp/index. html, 2019.11

8. JMA (Japan Meteorological Agency, Historical Data Search, https://www. data.jma.go.jp/gmd/risk/obsdl/index. php\#!table, Long-term trend in sea surface temperature (around Japan),

9. https://www.data.jma.go.jp/gmd/ kaiyou/data/shindan/a_1/japan_warm/ japan_warm.html, Changes so far in heavy rains, hot days, etc. (extreme events), https:/ / www.data.jma.go.jp/cpdinfo/ extreme/extreme_p.html ,2018.11

10. Kyushu Regional Development Bureau, Ministry of Land, Infrastructure and Transport (2017), Report of the Technical Study Committee for River and Erosion Control Restoration in the Right Bank of the Chikugo River Basin (Part 2), www.qsr.mlit.go.jp/site_files/file/ bousai_joho/tecforce/H29hokubugouu data/171122houkokusyo2.pdf, 2018.11

\section{References}

Benda, L.E., Sias, J.C. (2003) A quantitative framework for evaluating the mass balance in-stream organic debris. Forest Ecology and Management Vol. 172, p. 1-16.

Benke, A.C., Wallace, B.J. (2003) Influence of wood on invertebrate communitites in streams and rivers. In Gregory, Boyer and Gurnell (Eds.). The ecology and management of wood in world rivers symposium proceedings, p. 149-177.

Blong, R. (1981) Some effects of tephra falls on buildings. S. Self, R.S.J. Sparks (Eds.). Tephra Studies. p. 405-420.

Chaithong, T., Komori, D., Sukegawa, Y., Anzai, S. (2018) Estimating woody debris recruitment in a stream caused by a typhoon-induced landslide: a case study of typhoon Lionrock in Iwaizumi, Iwate Prefecture, Japan. Geomatics, Natural Hazards and Risks vol. 9, p. 10711084.

Chen, J., Wang, D., Zhao, W., Chen, H., Wang, T., Nepal, N., Chen, X. (2020) Laboratory study on the characteristics of large wood and debris flow processes at slit-check dams. Landslides vol. 17, p. 1703-1711.

Comiti, F. (2012) How natural are alpine mountain rivers? Evidence from the Italian Alps. Earth Surface Proceses and Landforms vol. 37, p. 693-707.

Comiti, F., Agostino, V.D., Moser, M., Lenzi, M.A., Bettella, F., Agnese, A.D., Rigon, E., Gius, S., Mazzorana, B. (2012) Preventing wood-related hazards in mountain basins: from wood load estimation to designing retention structures. 12th INTERPRAEVENT congress 2012 Grenoble, France, Conference proceedings p. 651-662.

Conley, W., Kramer, N. (2020) Riverine large wood and recreation safety: A framework to discretize and contextualize hazard. Earth Surface Processes and Landforms vol. 45, p. 2201-2216.

Cullen, A., Frei, H. (1999) Probabilistic Techniques in Exposure Assessment: Plenum Publishing.

Delignette-Muller, M.L., Dutang, C. (2020) Fitdistrplus: An R Package for Fitting Distributions. Available online:https://cran.r-project.org/web/packages/fitdistrplus/vignettes/ paper2JSS.pdf [1st October 2020]

Diehl, T.H. (1997) Potential drift accumulation at bridges. Report FHWA-RD-97028 of the US Department of Transportation, Federal highway Administration.

Efron, B. (1979) Bootstrap methods: another look at the jackknife. Annals of Statistics vol. 7, p. 
$1-26$.

Efron, B. (1981) Nonparametric estimates of standard error: the jackknife, the bootstrap, and other methods. Biometrika vol. 65, p. 589-599.

Gomez, C. (2018) The Asakura Sediment and Tree Disaster: Drifted Wood Distribution and Flow Dynamics from UAV and Aircraft Remote Sensing. Seminar at the Ministry of Land, Infrastructure and Transport, SABO division, Tsukuba University (June 2018).

Gurnell, A. (2013) Wood in fluvial systems, Treatise on Geomorphology vol. 9, p. 163-188.

Iroume, A., Cartagena, M., Villablanca, L., Sanhueza, D., Mazzorana, B. Picco, L. (2020) Long-term large wood load fluctuations in two low-order streams in Southern Chile. Earth Surface Processes and Landforms vol.45, Issue 9, p. 1959-1973.

Kimura, N., Tai, A., Hashimoto, A. (2017) Flood caused by driftwood accumulation at a bridge. International Journal of Disaster Resilience in the Built Environment vol. 8. p.466-477.

Komatsu, M., Uchida, T., Sakurai, W. (2019) An analysis for premonitory phenomena from recent sediment-related disasters. Journal of the Japan Society of Erosion Control Engineering vol.72, No.1 p.37-44

Le Lay, Y.F., Piegay, H., Moulin, B. (2013) Wood entrance, deposition, transfer and effects on fluvial forms and processes: problem statements and challenging issues, Treatise of Geomorphology vol. 12, p. 20-36.

Li, M., Hasemi, Y., Nozoe, Y. (2019) Study on disaster risks and countermeasures influenced by the impact of the modernization process in historical mountain villages: A case study of Hanazawa historical village, Japan. International Journal of Disaster Risk Reduction vol. 41, p. 1-14.

Lucia, A., Schwientek, M., Eberle, J., Zarfl, C. (2018) Planform changes and large wood dynamics in two torrents during a severe flash flood in Braunsbach, Germany 2016. Science of the Total Environment vol. 640-641, p. 315-326.

Lyn, D., Cooper, T., Condon, D., Gan, L. (2007) Factors in debris accumulation at bridge piers. Department of Transportation, Federal Highway Administration Research and Development, Turner-Fairbank Highway Research Centre, Washington.

Nakatani, K., Kosugi, M., Satofuka, Y., Mizuyama, T. (2016) Debris-flow Flooding and Debris Deposition Considering the Effect of Houses: Disaster Verification and Numerical Simulation. International Journal of Erosion Control Engineering vol. 9, p. 145-154.

Sahara, K., Ikeda, T., Iwai, Y., Kakuta, K., Kanazawa, A., Gonda, Y., Saitou, Y., Shuin, Y., Tagata, S., Fujita, M., Miyata, S., Miwa, H. (2019) Sediment disasters in Shikoku region in July, 2018. Journal of the Japan Society of Erosion Control Engineering vol.71, No.5, p. 43-53

Sato, H., Nagasawa, Y., Asai, T., Terazawa, K. (2006) Quantification of the woody debris in Appetsu river basin by Typhoon 0310, Etsu. Journal of the Japan Society of Erosion Control Engineering, vol.58, No.6, p.11-17

Shimizu, O., Kodama, R., Kasai, M. (2018) Proposal of a new idea for designating hazard areas based on travel distance of sediment and woody debris discharged from rainfall-induced landslides in Aso caldera walls. Journal of the Japan Society of Erosion Control Engineering, vol.70, No.5, p.3-14

Steeb, N., Rickenmann, D., Badoux, A., Rickli, C., Waldner, P. (2017) Large wood recruitment processes and transported volumes in Swiss mountain streams during the extreme flood of 
august 2005. Geomorphology vol. 279, p. 112-127.

Tanaka, T., Tsuchiya, S., Yukawa, N., Furuta, K., Nakazawa, K. (2019) Landslides and sediment runoff caused by the long-duration rain of July 2018 in Gujo-shi, Gifu prefecture. Journal of the Japan Society of Erosion Control Engineering vol.71, No.5, p38-42

Wohl, E., Cenderelli, D.A., Dwire, K.A., Ryan-Burkett, S.E., Young, M.K., Fausch, K.D. (2010) Large in-stream wood studies: A call for common metrics. Earth Surface Processes and Landforms vol. 35, p. 618-625.

Yamada, K., Nagasaka, Y., Tsushima, T., Abe, T. (2006) Quantitative study of the area of damage and the amount of lost or trapped timber in a riparian forest in the Appetsu River basin caused by Typhoon 0310 (Etau). Journal of the Japan Society of Erosion Control Engineering vol.59, No.1, p.13-20 